\title{
Clinical relevance of ticagrelor monotherapy following 1-month dual antiplatelet therapy after bifurcation percutaneous coronary intervention: Insight from GLOBAL LEADERS trial
}

\author{
Norihiro Kogame MD ${ }^{1,2}$ | Ply Chichareon MD ${ }^{1,3}$ | Kenneth De Wilder $M^{4}$ | \\ Kuniaki Takahashi MD ${ }^{1}$ | Rodrigo Modolo MD ${ }^{1,5}$ | Chun Chin Chang MD ${ }^{6}$ (1) | \\ Mariusz Tomaniak MD ${ }^{6}$ (1) | Hidenori Komiyama MD ${ }^{1}$ | Alaide Chieffo MD ${ }^{7}$ | \\ Antonio Colombo MD ${ }^{8}$ | Scot Garg MD, PhD ${ }^{9}$ | Yves Louvard MD $^{10}$ | \\ Peter Jüni MD ${ }^{11,12}$ | Philippe G. Steg MD ${ }^{13}$ | Christian Hamm MD ${ }^{14}$ | \\ Pascal Vranckx MD, PhD ${ }^{15}$ | Marco Valgimigli MD, $\mathrm{PhD}^{16}$ (] | \\ Stephan Windecker MD ${ }^{16}$ | Hans-Peter Stoll MD ${ }^{17}$ | Yoshinobu Onuma MD, PhD ${ }^{6}$ | \\ Luc Janssens $\mathrm{MD}^{4}$ | Patrick W. Serruys MD, $\mathrm{PhD}^{18}$ [
}

\footnotetext{
${ }^{1}$ Department of Cardiology, Amsterdam University Medical Center, Amsterdam, The Netherlands

${ }^{2}$ Department of Cardiology, Toho University medical center Ohashi hospital, Tokyo, Japan

${ }^{3}$ Faculty of Medicine, Division of Cardiology, Department of Internal Medicine, Prince of Songkla University, Songkhla, Thailand

${ }^{4}$ Heart Centre, Imelda Hospital Bonheiden, Bonheiden, Belgium

${ }^{5}$ Cardiology Division, Department of Internal Medicine, University of Campinas (UNICAMP), Campinas, Brazil

${ }^{6}$ Department of Interventional Cardiology, Thoraxcenter, Erasmus Medical Center, Rotterdam, The Netherlands

${ }^{7}$ Interventional Cardiology Unit, IRCCS San Raffaele Scientific Institute, Milan, Italy

${ }^{8}$ Interventional Cardiology Unit, Villa Maria Cecila Hospital GVM, Cotignola (RA), Italy

${ }^{9}$ Department of Cardiology, Royal Blackburn Hospital, Blackburn, UK

${ }^{10}$ Department of Cardiology, Ramsay Générale de Santé, Institut Cardiovasculaire Paris Sud, Hopital Privé Jacques Cartier, Massy, France

${ }^{11}$ Applied Health Research Centre, Li Ka Shing Knowledge Institute of St Michael's Hospital, Toronto, Ontario, Canada

${ }^{12}$ Department of Medicine and Institute of Health Policy, Management and Evaluation, University of Toronto, Toronto, Ontario, Canada

${ }^{13}$ French Alliance for Cardiovascular Trials (FACT), Université Paris-Diderot, Paris, France

${ }^{14}$ Kerckhoff Heart and Thorax Center, University of Giessen, Giessen, Germany

${ }^{15}$ Faculty of Medicine and Life Sciences, Jessa Ziekenhuis, the Hasselt University, Hasselt, Belgium

${ }^{16}$ Department of Cardiology, Inselspital, University of Bern, Bern, Switzerland

${ }^{17}$ Biosensors Clinical Research, Morges, Switzerland

${ }^{18}$ International Centre for Circulatory Health, Imperial College London, London, UK
}

Correspondence

Patrick W. Serruys, International Centre for Circulatory Health, Imperial College London, London, United Kingdom.

Email: patrick.w.j.c.serruys@gmail.com

Funding information

AstraZeneca; Biosensors International Group

Medicines company

\section{Abstract}

Background: The aim of this study was to investigate the impact of ticagrelor monotherapy following 1-month dual antiplatelet therapy (DAPT) after percutaneous coronary intervention ( $\mathrm{PCl}$ ) for bifurcation lesions.

Methods: GLOBAL LEADERS was a randomized, superiority, all-comers trial comparing 1-month DAPT with ticagrelor and aspirin followed by 23-month ticagrelor monotherapy (experimental treatment) with standard 12-month DAPT followed by 
12-month aspirin monotherapy (reference treatment) in patients treated with a biolimus A9-eluting stent. The primary endpoint was a composite of all-cause death or new Q-wave myocardial infarction (MI) at 2 years.

Results: Among the 15,845 patients included in this subgroup analysis, 2,498 patients (15.8\%) underwent $\mathrm{PCl}$ for at least one bifurcation lesion. The incidence of the primary endpoint was similar between the bifurcation and nonbifurcation groups (4.7 vs. 4.0\%, $p=.083)$. The experimental treatment had no significant effect on the primary endpoint according to the presence/absence of a bifurcation lesion (bifurcation: hazard ratio [HR]: 0.74, 95\% confidence interval [Cl]: 0.51-1.07; nonbifurcation: $\mathrm{HR}: 0.90,95 \% \mathrm{Cl}$ : 0.76-1.07, $p$ for interaction $=.343$ ), but was associated with significant reduction in definite or probable stent thrombosis ( $p$ for interaction $=.022$ ) and significant excess of stroke ( $p$ for interaction $=.018$ ) when compared with the reference treatment.

Conclusions: After PCl for bifurcation lesions using 1-month of DAPT followed by ticagrelor monotherapy for 23 months did not demonstrate explicit benefit regarding all-cause death or new Q-wave $\mathrm{MI}$ as in the overall trial.

\section{KEYWORDS}

antiplatelet treatment, bifurcation lesion, drug-eluting stents, Percutaneous coronary intervention

\section{1 | INTRODUCTION}

Bifurcation lesions are associated with a lower rate of procedural success and a higher risk of complications compared to nonbifurcation lesions in patients treated with percutaneous coronary intervention (PCl). ${ }^{1,2}$ A number of randomized controlled trials have investigated the optimal intervention strategy in patients with bifurcation lesions and showed no benefit in terms of clinical outcomes for the systematic two-stent approach versus main branch-only stenting with provisional stenting of the side branch. ${ }^{2}$ Therefore, this provisional side branch stenting strategy is the recommended treatment of bifurcation lesions with a Class IA recommendation in current guidelines. ${ }^{3}$ In $5-25 \%$ of cases, a second stent for the side branch may be needed ${ }^{4-6}$; however, the best two-stent technique to use in these situations remains debatable. ${ }^{3}$

The complexity and the numerous subtypes of two-stent techniques render their comparison difficult. For that reason, the European bifurcation club introduced the Main, Across, Distal, Side (MADS) classification to standardize reports that allow comparison between studies and facilitate interpretation of published results in the evolving literature. ${ }^{7,8}$ In the GLOBAL LEADERS trial, the dedicated electronic case record form (eCRF)-based MADS classification was achieved in all site-reported bifurcation lesions, which represents a unique opportunity to analyze a cohort stratified for the presence of bifurcation lesions within a large contemporary $\mathrm{PCl}$ trial. ${ }^{9}$

In terms of antiplatelet therapy, although the increased complexity of $\mathrm{PCl}$ including two-stent technique for bifurcation lesions represent a driver for favoring more prolonged dual antiplatelet therapy (DAPT), the evidence regarding the optimal duration of DAPT based on the complexity of intervention is limited, especially due to the low prevalence of bifurcation $\mathrm{PCl}$ in the previous clinical trials. ${ }^{10,11}$ Furthermore, the role of potent $\mathrm{P} 2 \mathrm{Y} 12$ inhibitors after bifurcation $\mathrm{PCl}$ is uncertain.

In this prespecified subgroup analysis of the primary endpoint such as all-cause death and new Q-wave myocardial infarction (MI) from the GLOBAL LEADERS trial, ${ }^{12}$ we sought to investigate the impact of ticagrelor monotherapy following 1-month DAPT after bifurcation PCI.

\section{2 | METHODS}

\section{1 | The GLOBAL LEADERS trial}

The design and main results of the GLOBAL LEADERS trial have been published previously. ${ }^{13}$ Briefly, it was a prospective, multicenter, randomized, open-label, superiority trial comparing two antiplatelet regimens in 15,991 all-comers patients who were exclusively treated with a biolimus A9-eluting stent for stable coronary artery disease or acute coronary syndromes.

Patients were randomly assigned in a 1:1 fashion to 1-month DAPT with aspirin and ticagrelor followed by 23 months of ticagrelor monotherapy (experimental treatment), or standard DAPT with aspirin plus either clopidogrel (for patients with stable coronary artery disease) or ticagrelor (for patients with acute coronary syndromes) for 12 months, followed by aspirin monotherapy for 12 months (reference treatment). Regarding the primary endpoint of all-cause death or new Q-wave MI at 2 years, the overall trial failed to demonstrate the superiority of experimental treatment compared with the reference treatment $(3.81 \%$ in the experimental treatment vs. $4.37 \%$ in the reference treatment, 
$p=.073)$, although at 1 year, the superiority of experimental treatment was demonstrated (1.95 vs. $2.47 \%, p=.028$ ).

The trial was approved by the institutional review board at each investigating center. The study followed the ethical principles of the Declaration of Helsinki. All the participants provided written informed consent at the time of participation in the trial. The trial is registered with ClinicalTrials.gov, number NCT01813435.

\subsection{Study population and data collection}

According to the all-comers concept, only a limited number of inclusion and exclusion criteria were applied in the GLOBAL LEADERS trial (Data S1).

In this prespecified subgroup analysis of primary endpoint, patients undergoing bifurcation $\mathrm{PCl}$ were identified from the dedicated e-CRFbased MADS classification reported by investigators. Bifurcation lesions were defined by investigators in accordance with the practical definition of the European Bifurcation Club, as "a coronary artery narrowing occurring adjacent to, and/or involving the origin of a significant side branch." All bifurcation PCls were classified whether treated with one- or two-stent technique using the results of the MADS classification. Three-stent techniques such as "extended V" and "trouser legs and seat" were included in the two-stent technique. The stenting technique for trifurcation lesion is not covered by the MADS classification, therefore trifurcation was identified according to the definition of SYNTAX score. ${ }^{14}$ The choice of bifurcation treatment technique was left to the discretion of the operators.

As many as seven on-site monitoring visits were done at individual sites, with $20 \%$ of reported events checked against source documents. Additionally, the trial was monitored for event underreporting and event definition consistency. However, no overall central independent adjudication of clinical events was implemented.

\section{3 | Endpoint definitions}

The primary endpoint was the composite of all-cause death or new Qwave $\mathrm{MI}$ up to 2 years after randomization. Deaths from any cause were ascertained without adjudication, ${ }^{15}$ due to the fact that the survival data were derived from thorough site reports and search for vital status obtained from public domains. Q-wave MI was centrally adjudicated and defined in compliance with the Minnesota classification (new major Q-QS wave abnormalities) or by the appearance of a new left bundle branch block in conjunction with abnormal biomarkers.

The secondary endpoints included individual components of the primary endpoint (all-cause death and new Q-wave Ml); composite of all-cause death, stroke, or new Q-wave Ml; any stroke; ischemic stroke; any Ml; any revascularization; target vessel revascularization (TVR); definite stent thrombosis (ST); definite or probable $\mathrm{ST}^{16}$; and bleeding defined according to the Bleeding Academic Research Consortium criteria (type 3 or 5) up to 2 years. ${ }^{17}$

The third universal definition of $\mathrm{MI}$ was the recommended criteria to report MI. $^{18}$ Composite endpoints were analyzed hierarchically. Individual components were reported nonhierarchically. ${ }^{19}$

\section{4 | Statistical analysis}

Clinical outcomes were compared between patients treated for at least one bifurcation lesion versus patients not treated for any bifurcation lesion (bifurcation vs. nonbifurcation).

Thereafter, the effect of experimental versus reference antiplatelet therapy on clinical outcomes according to presence/absence of bifurcation $\mathrm{PCl}$ was estimated with a Cox regression model.

Eventually, we did a subgroup analysis of the primary endpoint only in patients treated for at least one bifurcation lesion with tests for treatment-by subgroup interaction according to the prespecified baseline characteristics and the type of stenting technique such as one-stent and two-stent techniques. Due to the absence of classification for trifurcation $\mathrm{PCl}$ according to the MADS classification, patients with trifurcation $\mathrm{PCl}$ were excluded from the analysis comparing oneversus two-stent technique.

Categorical variables were compared with the $\chi 2$ test or Fisher's exact test. Continuous variables were compared with Student's $t$ test or MannWhitney $U$ test for nonnormally distributed data. Composite endpoints were calculated using time to first of any of the composite event(s) per patient. Patients started being at risk on the day of index $\mathrm{PCl}$ or if no procedure was performed on the day of randomization. Survival curves were constructed using Kaplan-Meier estimates, and the log-rank test was used to compare between-group differences. Landmark analyses were performed with prespecified cutoffs at 30 days (at the time of the planned date of discontinuation of aspirin in the experimental treatment) and 1 year (at the time of the planned dates of discontinuation of a P2Y12 inhibitor in the reference treatment). In total, there were six outpatient protocol visits at 30 days, $3,6,12,18$, and 24 months. A two-sided $p$ value of less than .05 was considered to indicate statistical significance. All statistical analyses were done in SPSS (version 25.0.0, IBM, New York, NY).

\section{3 | RESULTS}

The GLOBAL LEADERS trial recruited a total of 15,991 patients, ${ }^{13}$ of whom 146 patients were excluded from this analysis (Figure 1), leaving 15,845 patients of which 2,498 patients (15.7\%) underwent $\mathrm{PCl}$ for at least one bifurcation lesion and 7 patients $(0.04 \%)$ at least one trifurcation lesion. Among the patients with at least one bifurcation lesion, 2002 (80.1\%) were treated with $\mathrm{PCl}$ using a one-stent technique and 489 (19.6\%) using a two-stent technique (Figure 1).

\section{1 | Clinical outcomes: Bifurcation versus nonbifurcation groups}

Patients in the nonbifurcation group had a higher body mass index and higher prevalence of diabetes mellitus or previous revascularization, whereas patients in the bifurcation group more often presented with acute coronary syndrome (Table 1 ). In terms of procedural characteristics, patients in the bifurcation group as expected had more lesions, stents, and longer total stent length per patient. 


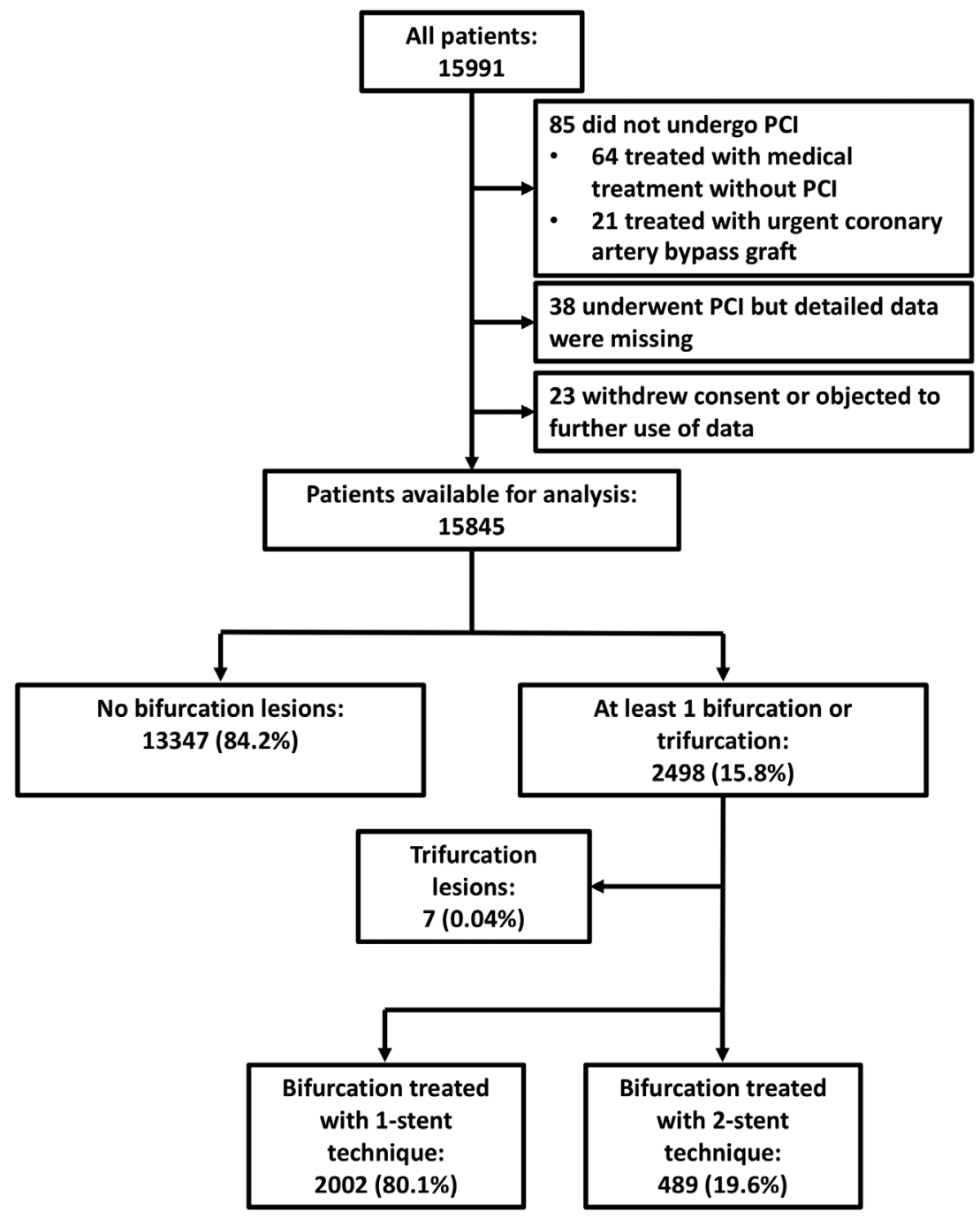

FIGURE 1 Study flow chart

In terms of the primary endpoint (a composite of all-cause death or new Q-wave $\mathrm{MI}$ ) at 2 years, there was a trend toward a higher incidence in the bifurcation group compared with the nonbifurcation group (4.72 vs. 3.98\%, hazard ratio (HR): $1.19,95 \%$ confidence interval [95\% Cl]: 0.98-1.46, $p=.083$ ), a difference driven by the significantly higher incidence of new Qwave $\mathrm{Ml}$ in the bifurcation group $(1.84$ vs. $1.04 \%, \mathrm{HR}: 1.78,95 \% \mathrm{Cl}$ $1.27-2.48, p=.001$ ) (Table 2). The incidences of any revascularization at 2 years were higher in the bifurcation group versus nonbifurcation group (11.21 vs. 9.19\%, HR: $1.24,95 \% \mathrm{Cl}: 1.09-1.41, p=.001$ ), as well as TVR at 2 years (6.69 vs. $4.83 \%$, HR: $1.40,95 \%$ Cl: $1.18-1.66, p<.001$ ) (Table 2 ). These differences in any revascularization and TVR were also observed at 30-day and 1-year follow-up, but not in the landmark analysis at 1 year.

\section{2 | Treatment effect of antiplatelet therapy according to presence/absence of bifurcation lesions}

There were no significant differences in baseline characteristics between experimental and reference groups stratified by presence/absence of bifurcation lesions (Table S1).

The results for the experimental versus reference antiplatelet treatment in the bifurcation and nonbifurcation groups are reported in
Figure 2 and Table S2. Compared to the reference strategy, the experimental strategy did not reduce the primary endpoint at 2 years in patients undergoing $\mathrm{PCl}$ irrespective of the presence or absence of a bifurcation lesion (bifurcation: HR: $0.74,95 \% \mathrm{Cl}$ : 0.51-1.07; nonbifurcation: HR: $0.90,95 \% \mathrm{Cl}$ : 0.76-1.07, $p$ for interaction $=.343$ ); however, it did result in a significant reduction in rates of definite or probable ST at 2 years in patients in the bifurcation group (HR: 0.46 , $95 \% \mathrm{Cl}: 0.22-0.97)$ versus nonbifurcation group (HR: $1.20,95 \% \mathrm{Cl}$ : 0.85-1.69, $p$ for interaction $=.022$ ) (Figure S1a). The same trend was observed on 1-year definite or probable ST ( $p$ for interaction $=.027$ ), whereas this significant benefit of ticagrelor monotherapy against aspirin monotherapy subsided beyond 1 year $(p$ for interaction $=.482$ ) (Figure S1b). In terms of the 2-year incidence of stroke, the experimental strategy showed a negative effect in patient undergoing bifurcation $\mathrm{PCl}$ against the reference strategy (bifurcation: HR: 2.72, 95\% Cl: 1.06-6.94 in Figure S2a; nonbifurcation: HR: 0.82, 95\% Cl: 0.58-1.14, $p$ for interaction $=.018$ ). This negative effect was observed at 1 year follow-up ( $p$ for interaction $=.021$ ), but not at 30 days ( $p$ for interaction $=.480$ ) and beyond 1 year ( $p$ for interaction $=.479$ ). In patients undergoing bifurcation $\mathrm{PCl}$, the majority of stroke was ischemic (experimental 
TABLE 1 Baseline and procedural characteristics

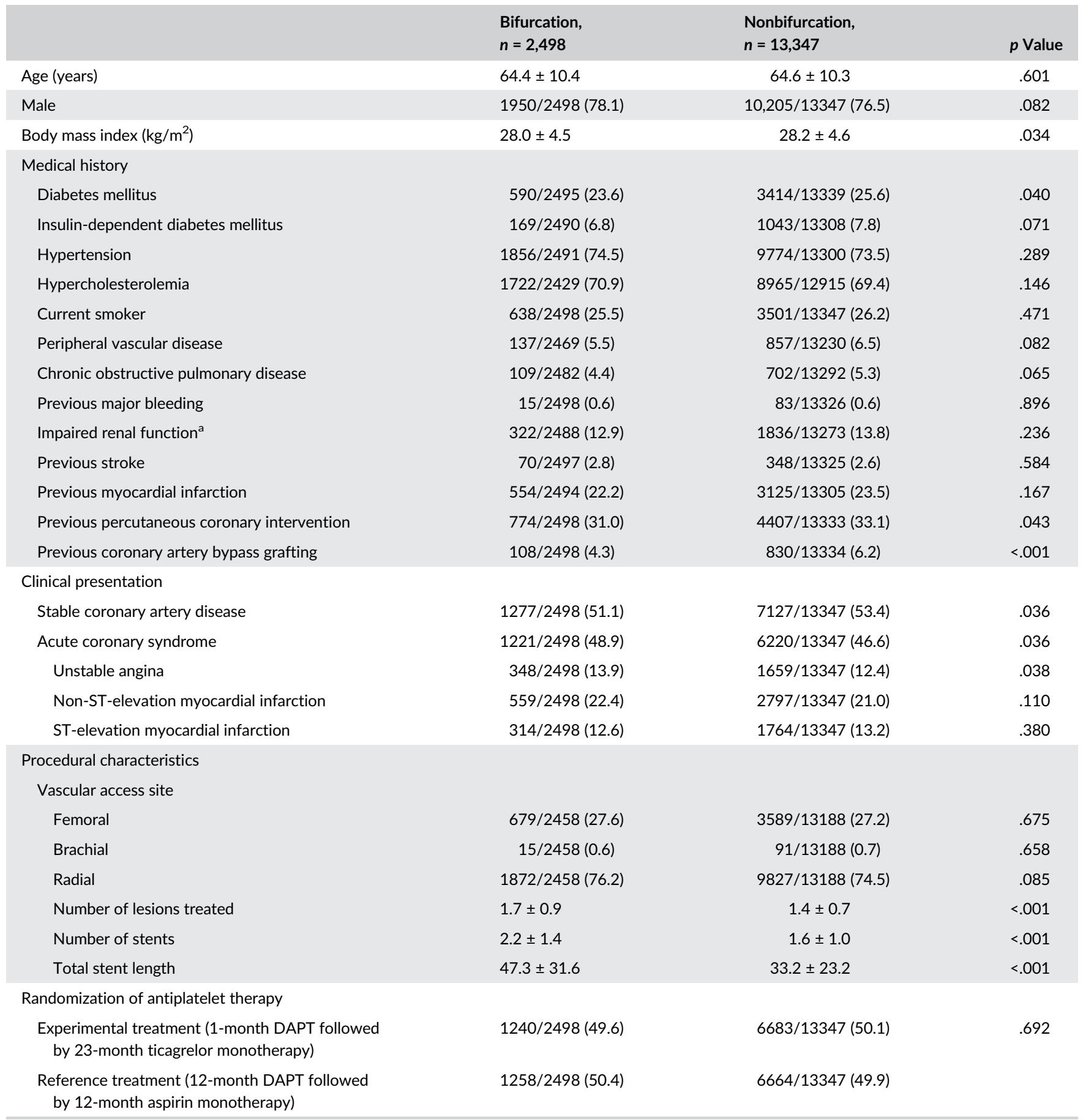

Note: Data are mean \pm SD or counts (percentage).

Abbreviations: DAPT, dual antiplatelet therapy; ST, stent thrombosis.

${ }^{a}$ Impaired renal function is defined as estimated glomerular filtration rate of creatinine clearance of $60 \mathrm{~mL} / \mathrm{min}$ per $1.73 \mathrm{~m}^{2}$ based on the Modification of Diet in Renal Disease formula.

group: 13/16 [81.2\%], reference group: 6/6 [100\%]), and the incidence of ischemic stroke was not different between groups (experimental group: $1.0 \%$ vs. reference group: $0.5 \%, \mathrm{HR} 2.21,95 \% \mathrm{Cl}$ : 0.84-5.80, $p=.109$ in Figure S2b). Only three hemorrhagic strokes occurred in patient undergoing bifurcation $\mathrm{PCl}$, two occurred in the first year (days 135 and 139) and the third one beyond 1 year (day 596) (experimental group: $0.2 \%$ vs. reference group: $0.0 \%, p=.081$ in Figure $\mathrm{S} 2 \mathrm{c}$ ).

\subsection{Subgroup analysis of the primary endpoint in patients treated for at least one bifurcation lesion}

The subgroup analysis in patients with bifurcation $\mathrm{PCl}$ demonstrated no variation in treatment effects for the primary endpoint according to prespecified baseline characteristics as well as stenting technique (one- vs. two-stent technique) (Figure 3). In patients treated with two- 
TAB LE 2 Clinical outcomes at 30 days, 1 and 2 years follow-up and landmark analysis at 30 days and 1 year stratified by presence or absence of bifurcation

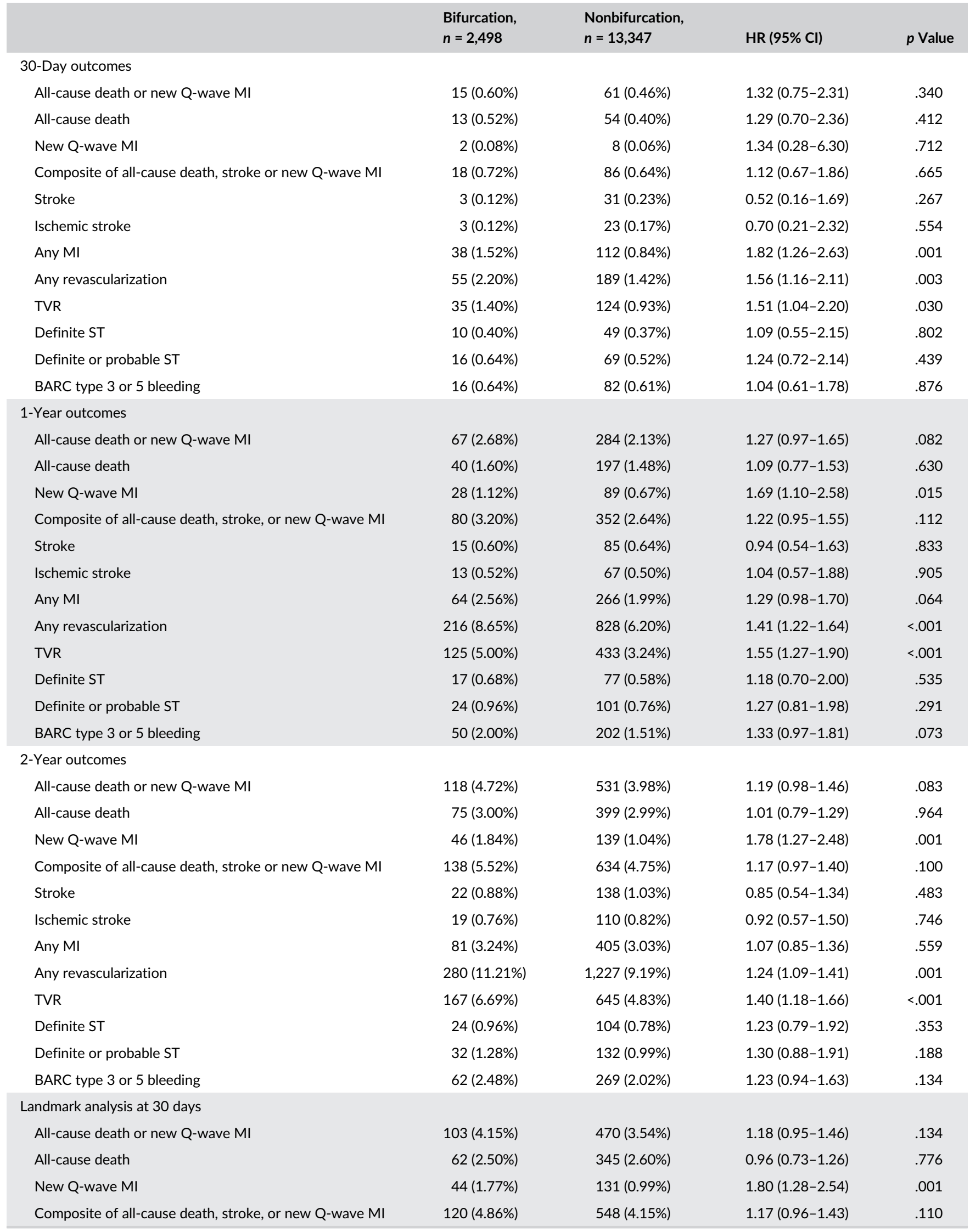


TABLE 2 (Continued)

\begin{tabular}{|c|c|c|c|c|}
\hline & $\begin{array}{l}\text { Bifurcation, } \\
n=2,498\end{array}$ & $\begin{array}{l}\text { Nonbifurcation, } \\
n=13,347\end{array}$ & $\mathrm{HR}(95 \% \mathrm{Cl})$ & $p$ Value \\
\hline Stroke & 19 (0.77\%) & 107 (0.81\%) & $0.95(0.58-1.54)$ & .831 \\
\hline Any MI & $43(1.76 \%)$ & $293(2.23 \%)$ & $0.79(0.57-1.09)$ & .145 \\
\hline Any revascularization & 225 (9.29\%) & $1,038(7.96 \%)$ & $1.18(1.02-1.36)$ & .025 \\
\hline Definite or probable ST & $16(0.65 \%)$ & $63(0.48 \%)$ & $1.36(0.78-2.35)$ & .275 \\
\hline BARC type 3 or 5 bleeding & $46(1.87 \%)$ & $187(1.42 \%)$ & $1.32(0.96-1.82)$ & .092 \\
\hline \multicolumn{5}{|l|}{ Landmark analysis at 1 year } \\
\hline All-cause death or new Q-wave MI & $51(2.10 \%)$ & 247 (1.89\%) & $1.11(0.82-1.50)$ & .500 \\
\hline Stroke & $7(0.29 \%)$ & $53(0.41 \%)$ & $0.70(0.32-1.55)$ & .382 \\
\hline Ischemic stroke & $6(0.25 \%)$ & $43(0.33 \%)$ & $0.75(0.32-1.75)$ & .498 \\
\hline Any MI & $17(0.72 \%)$ & 139 (1.09\%) & $0.65(0.40-1.08)$ & .097 \\
\hline Any revascularization & $64(2.88 \%)$ & 399 (3.28\%) & $0.87(0.67-1.14)$ & .318 \\
\hline TVR & $42(1.82 \%)$ & 212 (1.69\%) & $1.07(0.77-1.50)$ & .672 \\
\hline Definite ST & $7(0.29 \%)$ & 27 (0.21\%) & $1.39(0.60-3.18)$ & .440 \\
\hline Definite or probable ST & $8(0.33 \%)$ & $31(0.24 \%)$ & $1.38(0.63-3.00)$ & .419 \\
\hline BARC type 3 or 5 bleeding & $12(0.50 \%)$ & $67(0.52 \%)$ & $0.96(0.52-1.78)$ & .897 \\
\hline
\end{tabular}

Note: Data are counts (percentage).

Abbreviations: BARC, Bleeding Academic Research Consortium; MI, myocardial infarction; POCE, patient-oriented composite endpoint; ST, stent thrombosis; TVR, target vessel.

stent technique, the experimental treatment was associated with a numerically lower incidence of the primary endpoint at 2 years when compared with the reference treatment, but not statistically significant (4.6 vs. 9.1\%, HR: 0.50, 95\%Cl: 0.24-1.02, $p=.056$ ).

\section{4 | DISCUSSION}

The main findings of the study are following:

1. $\mathrm{PCl}$ for bifurcation lesions with a biolimus A9-eluting stent was not associated with higher incidence of primary endpoint of allcause death or new Q-wave $\mathrm{Ml}$ compared with $\mathrm{PCl}$ for nonbifurcation lesions, whereas significant difference was observed in new Q-wave MI, any revascularization, and TVR at 2 years between groups.

2. In patients who underwent bifurcation $\mathrm{PCl}$, 1-month of DAPT with aspirin and ticagrelor followed by 23-month ticagrelor monotherapy had no impact on the primary endpoint but was associated with significant reduction in the risk of definite or probable ST and significant excess of stroke compared with 12-month standard DAPT followed by 12-month aspirin monotherapy.

\section{1 | Bifurcation group versus nonbifurcation group}

In terms of the primary endpoint of death or new Q-wave MI, the result of the study is in line with previously published data from allcomers trials. ${ }^{1,20}$ In contrast, the higher rate of new Q-wave MI in the bifurcation group over the nonbifurcation group was observed consistently at 1- and 2-year follow-ups and in the landmark analysis at 1 year, whereas the incidence of any MI was similar between groups. In the bifurcation subanalysis of the Resolute all-comers trial, 2-year Q-wave MI rates in bifurcation and nonbifurcation groups were similar to the present trial, but there was no significant difference due to less sample size $(1.6 \%$ in bifurcation vs. $0.6 \%$ in nonbifurcation, $p=.097, n=2,265){ }^{20}$ Therefore, this finding may suggest that bifurcation $\mathrm{PCl}$ can be associated with the occurrence of more severe $\mathrm{MI}$ up to 2 years when compared with nonbifurcation $\mathrm{PCl}$.

\section{2 | Optimal duration of DAPT for patients undergoing bifurcation $\mathrm{PCI}$}

The evidence for the optimal antiplatelet strategy after bifurcation $\mathrm{PCl}$ is scarce, especially for potent antiplatelet drugs such as ticagrelor and prasugrel. Recent pooled patient-level analysis demonstrated that short DAPT of 3 or 6 months is associated with a higher incidence of 
1-year major adverse cardiac events mainly driven by $\mathrm{MI}$, when compared with prolonged DAPT of more than 1 year in patients undergoing $\mathrm{PCl}$ for complex lesions including bifurcation lesions treated with a two-stent technique. ${ }^{10}$ In addition, a multicenter observational study reported that the risks of a composite of all-cause death or $\mathrm{MI}, \mathrm{MI}$, and definite or probable ST at 4 years were significantly lower in the prolonged ( $\geq 12$ months) versus shorter DAPT group ( $<12$ months) after bifurcation $\mathrm{PCl}$ with drug-eluting stent (DES). ${ }^{21}$ From these results, it seems that patients undergoing bifurcation $\mathrm{PCl}$ need at least 12 months of DAPT. The present study also shows no benefit of 1-month DAPT followed by ticagrelor monotherapy on the primary endpoint when compared with 12-month DAPT.

\section{3 | ST and stroke after bifurcation PCI}

Previously coronary bifurcation lesions were reported as an independent risk factor for $\mathrm{ST}^{22-24}$ as consequence of several factors. Firstly, bifurcation stenting modifies local hemodynamics and creates low endothelial shear stress and stagnant areas that could result in local thrombogenicity. ${ }^{25}$ Secondly, pathological studies demonstrated that the flow divider zone was associated with a high percentage of uncovered struts and fibrin deposition several months after DES implantation, which could represent a substrate for ST. ${ }^{26}$ Thirdly, two-stent strategies have been suspected of inducing overlapping device segments that could result in local thrombogenicity. ${ }^{27}$ Finally, bifurcation stenting could also encourage stent malapposition due to vessel dimension variation along the different segments and promote future thrombotic events. ${ }^{28}$ In the present trial, the incidence of ST did not statistically differ between bifurcation and nonbifurcation groups. However, ticagrelor monotherapy following 1-month DAPT demonstrated significant treatment effect on definite or probable ST at 2 years compared with conventional aspirin monotherapy following 12-month DAPT. This benefit was observed up to 1 year and subsided beyond, although theoretically this benefit should be derived from the comparison between ticagrelor monotherapy versus aspirin monotherapy beyond 1 year. In addition, overall incidence of ST was quite low, and the treatment effect of the experimental strategy on ST went into opposite directions in bifurcation and nonbifurcation groups.
(A)

Death,
A)

eath or new $Q$ wave MI

Bifurcation: Yes 27/1240 (2.2) No

Bifurcation: Yes 15/1240(1.2) 25/1258 (2.0)

New $Q$ wave MI

Bifurcation: Yes $12 / 1240(1.0) \quad 16 / 1258(1.3)$

No $36 / 6683(0.5) \quad 53 / 6664(0.8)$

new Q-wave MI

Bifurcation: Yes $37 / 1240(3.0) \quad 43 / 1258(3.4)$

No $159 / 6683(2.4) \quad 193 / 6664(2.9)$

Stroke

Bifurcation: Yes $12 / 1240(1.0) \quad 3 / 1258(0.2) \quad 4.07(1.15-14.43)$

No $39 / 6683(0.6) \quad 46 / 6664(0.7) \quad 0.85(0.55-1.30)$

Ischemic stroke

Bifurcation: Yes 10/1240 (0.8)

No $29 / 6683(0.4)$

Any MI

Bifurcation: Yes $33 / 1240(2.7) \quad 31 / 1258(2.5) \quad 1.08(0.66-1.77)$

Any revascularization

No $143 / 6683(2.1) \quad 123 / 6664(1.8) \quad 1.16(0.92-1.48)$

Bifurcation: Yes $102 / 1240(8.2) \quad 114 / 1258(9.1) \quad 0.90(0.69-1.17)$

No $409 / 6683(6.1) \quad 419 / 6664(6.3) \quad 0.98(0.85-1.12)$ TVR

Bifurcation: Yes $59 / 1240(4.8) \quad 66 / 1258(5.2)$

No $205 / 6683(3.1) \quad 228 / 6664(3.4)$

Definite ST

Bifurcation: Yes $6 / 1240(0.5)$

Definite or probable ST

$47 / 6683(0.7) \quad 30 / 6664(0.5) \quad 1.57(0.99-2.48)$

Bifurcation: Yes $\quad 8 / 1240(0.6) \quad 16 / 1258(1.3) \quad 0.51(0.22-1.18)$

No $60 / 6683(0.9) \quad 41 / 6664(0.6) \quad 1.46(0.98-2.18)$

BARC 3 or 5 bleeding

Bifurcation: Yes $22 / 1240(1.8) \quad 28 / 1258(2.2) \quad 0.80(0.46-1.39)$

No $95 / 6683(1.4) \quad 107 / 6664(1.6) \quad 0.89(0.67-1.17)$

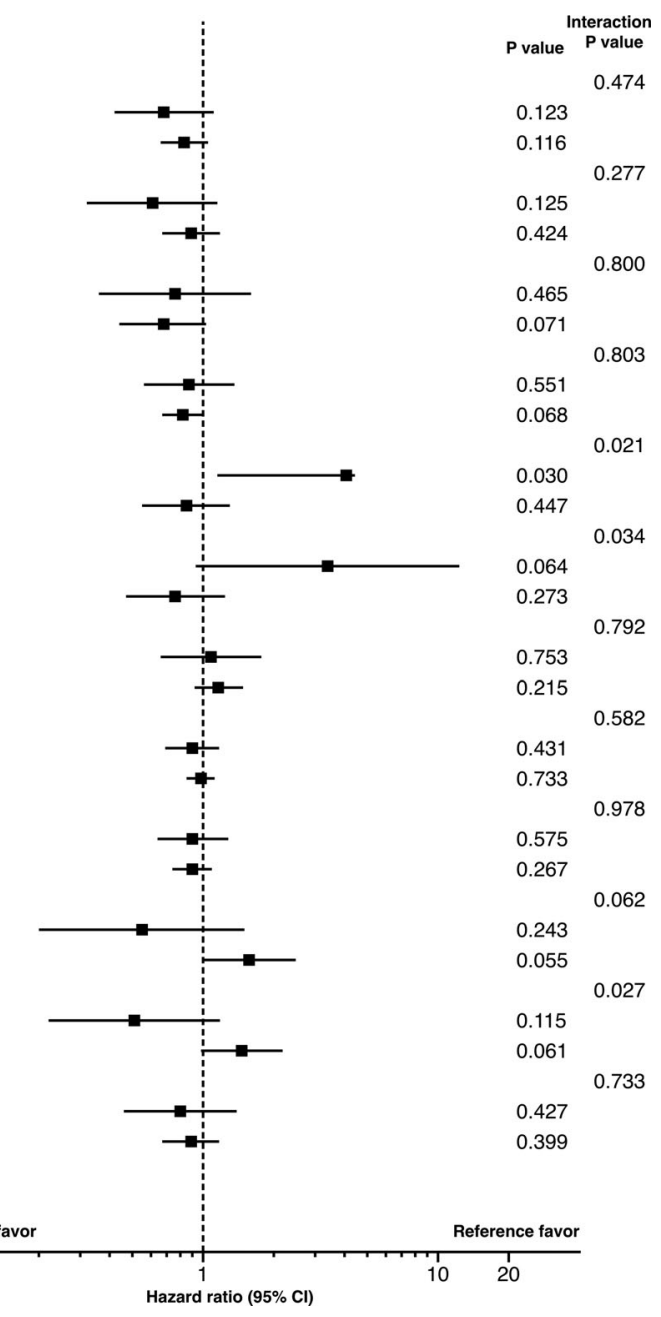

FIGURE 2 Treatment comparison of experimental versus reference antiplatelet strategy in randomized patients with versus without bifurcation PCl at 1 year (A) and 2 years (B) follow-up. BARC, Bleeding Academic Research Consortium; MI, myocardial infarction; $\mathrm{PCl}$, percutaneous coronary intervention; ST, stent thrombosis; TVR, target vessel revascularization 


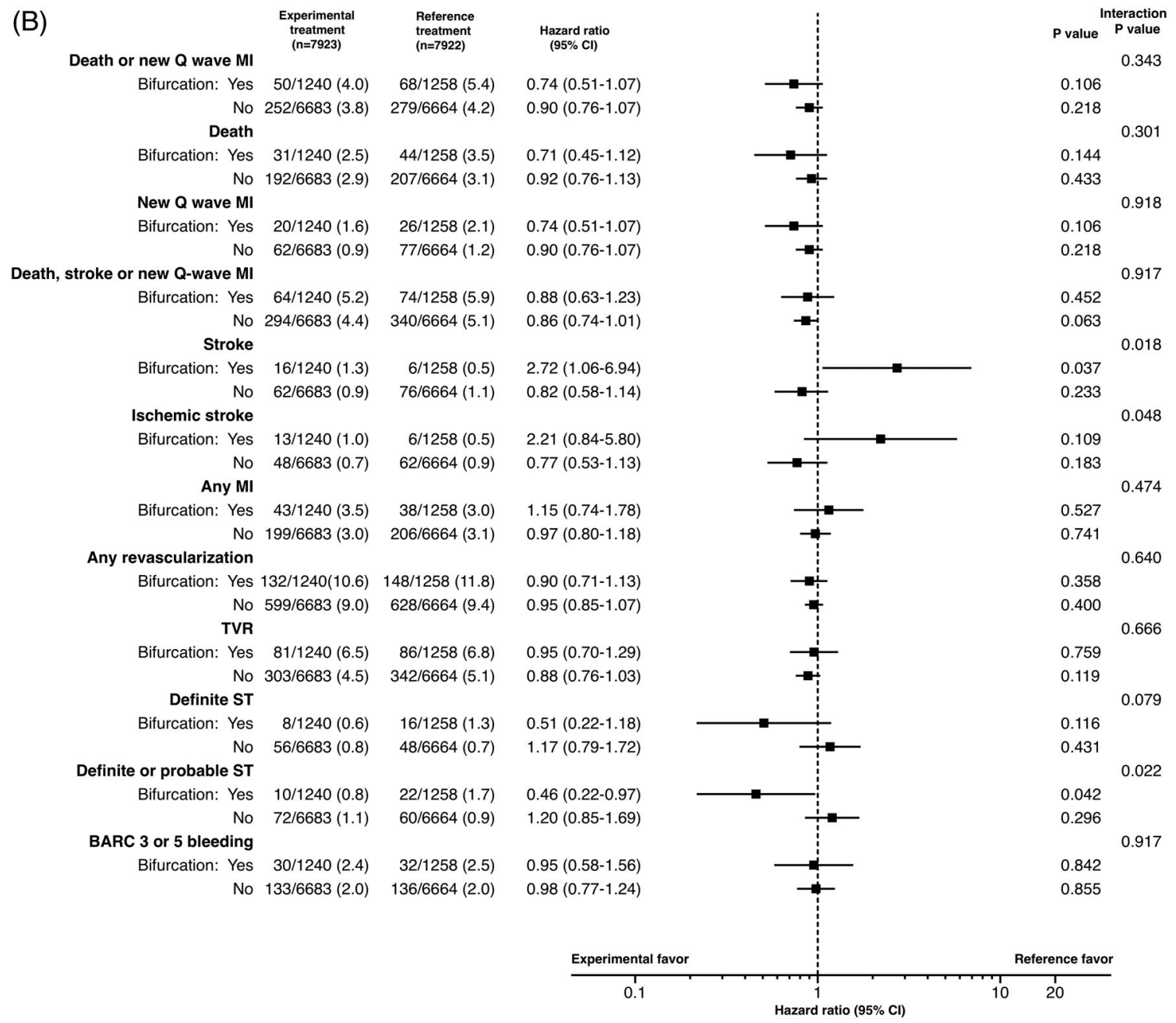

FIGURE 2 (Continued)

Consequently, these significant findings regarding ST can be considered as a play of chance.

On the other hand, in patients who underwent bifurcation $\mathrm{PCl}$, harmful effect of experimental treatment in 2-year stroke was observed compared with reference treatment. This difference in stroke was mainly derived from the result between 30 days and 1 year. Therefore, procedure itself was probably not associated with the occurrence of stroke. These findings may suggest that DAPT is associated with lower incidence of stroke up to 1 year compared with monotherapy of ticagrelor. However, overall incidence of stroke was quite low, and the treatment effect of the experimental strategy on stroke went into opposite directions in bifurcation and nonbifurcation groups. Consequently, these apparently significant findings regarding stroke can be also considered as a play of chance similar to ST.

Regarding composite hard endpoint of all-cause death, stroke, or new Q-wave $\mathrm{Ml}$ at 2 years, there was no significant difference between groups in patients undergoing bifurcation $\mathrm{PCl}$, which suggests that early discontinuation of aspirin at 30 days after bifurcation $\mathrm{PCl}$ followed by ticagrelor monotherapy may be as safe as conventional 12-month DAPT followed by aspirin monotherapy.
Further evidence from dedicated bifurcation trial testing 1-month DAPT followed by P2Y12 monotherapy is warranted in order to further elucidate that possible duality of effect (such as possible prevention of ST and possible increase in stroke) in patients undergoing bifurcation $\mathrm{PCl}$.

\section{4 | Study limitations}

This prespecified subgroup analysis of primary endpoint has several limitations.

Firstly, in the context of the overall trial in which the primary endpoint was not met, these findings need to be considered as hypothesis generating.

Secondly, although this subgroup analysis of primary endpoint was prespecified and information of bifurcation was prospectively collected, ${ }^{12}$ no formal power calculation was performed. In addition, there exist limitations inherent in subgroup analysis such as diminished power to detect real differences and increasing statistical likelihood of false finding when many subgroups are examined with 


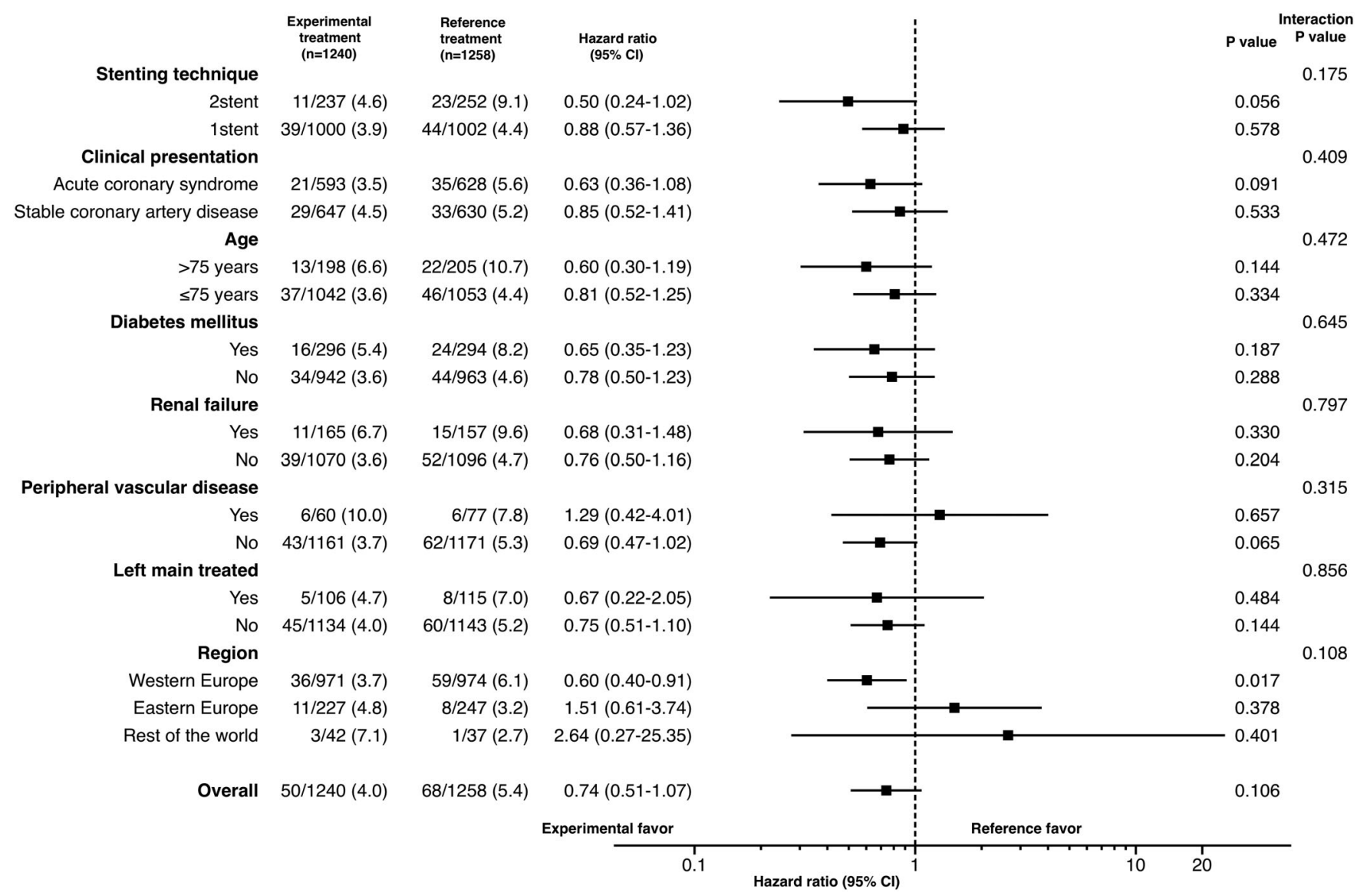

FIGURE 3 Subgroup analysis of all-cause death or new Q-wave MI at 2 years in patients treated for at least one bifurcation lesion. $\mathrm{Cl}$, confidence interval, $\mathrm{MI}$, myocardial infarction

multiple testing. Therefore, the study findings should be considered as hypothesis generating. ${ }^{29}$

Thirdly, clinical outcomes were not adjudicated by an independent clinical event committee. All events were identified and confirmed by the investigators of each hospital. There might be inaccuracies in determining cause of death or target vessel MI. Therefore, we chose all-cause death or new Q-wave MI centrally adjudicated by core lab instead of cardiac death or target vessel MI as the primary outcome. Nevertheless, the result of secondary endpoint should cautiously be interpreted in conjunction with the individual components of the primary endpoint.

Fourthly, the analysis for comparing two- versus one-stent technique was postrandomization and nonprespecified analysis; therefore, the findings are likely influenced by unmeasured confounders.

Fifthly, we did not collect the anatomic SYNTAX score including Medina classification in all the patients, which limited the analysis regarding anatomical complexity of each bifurcation lesion.

Finally, a biolimus A9-eluting stent has a relatively thicker strut of $120 \mu \mathrm{m}$ compared with other current-generation DES. This might result in worse outcomes in bifurcation lesions treated with two-stent technique using a biolimus A9-eluting stent due to the overlap of relatively thicker struts. A meta-analysis published in 2018 showed that DES with ultrathin struts (strut thickness $<70 \mu \mathrm{m}$ ) reduced the incidence of target lesion failure compared with that of contemporary stents with thicker struts. ${ }^{30}$ However, in the present study, all patients were exclusively treated with a biolimus A9-eluting stent, and this makes the effect of antiplatelet drug more likely.

\section{5 | CONCLUSIONS}

After PCl for bifurcation lesions, using 1-month of DAPT followed by ticagrelor monotherapy for 23 months did not demonstrate explicit benefit regarding all-cause death or new Q-wave $\mathrm{MI}$ as in the overall trial.

\section{DISCLOSURE OF INTERESTS}

Dr Ph Gabriel Steg reports research grant from Amarin, Bayer, Merck, Sanofi, and Servier, speaking or consulting fees from Amarin, Amgen, AstraZeneca, Bayer/Janssen, Boehringer-Ingelheim, Bristol-MyersSquibb, Idorsia, Lilly, Merck, Novartis, Novo-Nordisk, Pfizer, Regeneron, Sanofi, Servier. Dr Hamm reports personal fees from AstraZeneca. Dr Vranckx reports personal fees from AstraZeneca and the Medicines Company during the conduct of the study and personal fees from Bayer Health Care, Terumo, and Daiichi-Sankyo outside the submitted work. Dr Valgimigli reports grants and personal fees from 
Abbott, personal fees from Chiesi, personal fees from Bayer, personal fees from Daiichi Sankyo, personal fees from Amgen, grants and personal fees from Terumo, personal fees from Alvimedica, grants from Medicure, grants and personal fees from Astrazeneca, personal fees from Biosensors, outside the submitted work. Dr Windecker's institution has research contracts with Abbott, Amgen, Bayer, Biotronik, Boston Scientific, Edwards Lifesciences, Medtronic, St Jude Medical, Symetis SA, and Terumo, outside the submitted work. Dr Serruys reports personal fees from Abbott Laboratories, personal fees from Biosensors, personal fees from Cardialysis, personal fees from Medtronic, personal fees from Micel Technologies, personal fees from Sinomedical Sciences Technology, personal fees from St. Jude Medical, personal fees from Stentys, personal fees from Svelte Medical Systems, personal fees from Philips/Volcano, personal fees from Xeltis, personal fees from Stentlt, and personal fees from HeartFlow, outside the submitted work. The authors declare no potential conflict of interest.

\section{AUTHOR CONTRIBUTIONS}

N.K., P.C., Y.O., and P.W.S. analyzed the data and drafted the manuscript. K.D.W., A.C., A.C., S.G., Y.L., P.J., P.G.S., C.H., and L.J. contributed to data collection and to revise the manuscript critically for important intellectual content. K.T., R.M., C.C.C., M.T., H.K., and H.P.S. contributed to revise the manuscript critically for important intellectual content. P.V., M.V., S.W., and P.W.S. contributed to the conception and design of the study. P.W.S. gave final approval of the manuscript submitted.

\section{ORCID}

Chun Chin Chang (D) https://orcid.org/0000-0003-2799-1185

Mariusz Tomaniak (D) https://orcid.org/0000-0001-8289-1393

Marco Valgimigli (DD https://orcid.org/0000-0002-4353-7110

Patrick W. Serruys (D) https://orcid.org/0000-0002-9636-1104

\section{REFERENCES}

1. Grundeken MJ, Wykrzykowska JJ, Ishibashi $Y$, et al. First generation versus second generation drug-eluting stents for the treatment of bifurcations: 5-year follow-up of the LEADERS all-comers randomized trial. Catheter Cardiovasc Interv. 2016;87(7):E248-E260.

2. Gao XF, Zhang YJ, Tian NL, et al. Stenting strategy for coronary artery bifurcation with drug-eluting stents: a meta-analysis of nine randomised trials and systematic review. Eurolntervention. 2014;10 (5):561-569.

3. Neumann FJ, Sousa-Uva M, Ahlsson A, et al. ESC/EACTS guidelines on myocardial revascularization. Eur Heart J. 2019;40(2):87-165.

4. Hildick-Smith D, Behan MW, Lassen JF, et al. The EBC two study (European bifurcation coronary two): a randomized comparison of provisional T-stenting versus a systematic 2 stent culotte strategy in large caliber true bifurcations. Circ Cardiovasc Interv. 2016;9(9): e003643.

5. Zhang F, Dong L, Ge J. Simple versus complex stenting strategy for coronary artery bifurcation lesions in the drug-eluting stent era: a meta-analysis of randomised trials. Heart. 2009;95(20):1676-1681.
6. Brar SS, Gray WA, Dangas G, et al. Bifurcation stenting with drugeluting stents: a systematic review and meta-analysis of randomised trials. Eurolntervention. 2009;5(4):475-484.

7. Louvard Y, Thomas M, Dzavik V, et al. Classification of coronary artery bifurcation lesions and treatments: time for a consensus! Catheter Cardiovasc Interv. 2008;71(2):175-183.

8. Lassen JF, Burzotta F, Banning AP, et al. Percutaneous coronary intervention for the left main stem and other bifurcation lesions: 12th consensus document from the European Bifurcation Club. Eurolntervention. 2018;13(13):1540-1553.

9. Katsikis A, Chichareon P, Cavalcante R, et al. Application of the MADS classification system in a "mega mammoth" stent trial: feasibility and preliminary clinical implications. Catheter Cardiovasc Interv. 2019;93(1): 57-63.

10. Giustino G, Chieffo A, Palmerini T, et al. Efficacy and safety of dual antiplatelet therapy after complex PCI. J Am Coll Cardiol. 2016;68 (17):1851-1864.

11. Yeh RW, Kereiakes DJ, Steg PG, et al. Lesion complexity and outcomes of extended dual antiplatelet therapy after percutaneous coronary intervention. J Am Coll Cardiol. 2017;70(18):2213-2223.

12. Vranckx $P$, Valgimigli $M$, Windecker $S$, et al. Long-term ticagrelor monotherapy versus standard dual antiplatelet therapy followed by aspirin monotherapy in patients undergoing biolimus-eluting stent implantation: rationale and design of the GLOBAL LEADERS trial. Eurolntervention. 2016;12(10):1239-1245.

13. Vranckx $P$, Valgimigli $M$, Juni $P$, et al. Ticagrelor plus aspirin for 1 month, followed by ticagrelor monotherapy for 23 months vs aspirin plus clopidogrel or ticagrelor for 12 months, followed by aspirin monotherapy for 12 months after implantation of a drug-eluting stent: a multicentre, open-label, randomised superiority trial. Lancet. 2018;392(10151):940-949.

14. Serruys PW, Onuma Y, Garg S, et al. Assessment of the SYNTAX score in the Syntax study. Eurolntervention. 2009;5(1):50-56.

15. Hicks KA, Mahaffey KW, Mehran R, et al. Cardiovascular and stroke endpoint definitions for clinical trials. Circulation 2018. 2017;137(9):961-972.

16. Garcia-Garcia HM, McFadden EP, Farb A, et al. Standardized end point definitions for coronary intervention trials: the academic research Consortium-2 consensus document. Eur Heart J. 2018;39 (23):2192-2207.

17. Leon MB, Piazza N, Nikolsky E, et al. Standardized endpoint definitions for transcatheter aortic valve implantation clinical trials: a consensus report from the Valve Academic Research Consortium. Eur Heart J. 2011;32(2):205-217.

18. Thygesen K, Alpert JS, Jaffe AS, et al. Third universal definition of myocardial infarction. Eur Heart J. 2012;33(20):2551-2567.

19. Cutlip DE, Windecker S, Mehran R, et al. Clinical end points in coronary stent trials: a case for standardized definitions. Circulation. 2007;115(17):2344-2351.

20. Diletti R, Garcia-Garcia HM, Bourantas CV, et al. Clinical outcomes after zotarolimus and everolimus drug eluting stent implantation in coronary artery bifurcation lesions: insights from the RESOLUTE all comers trial. Heart. 2013;99(17):1267-1274

21. Jang WJ, Ahn SG, Song YB, et al. Benefit of prolonged dual antiplatelet therapy after implantation of drug-eluting stent for coronary bifurcation lesions: results from the coronary bifurcation stenting registry II. Circ Cardiovasc Interv. 2018;11(7):e005849.

22. lakovou I, Schmidt T, Bonizzoni E, et al. Incidence, predictors, and outcome of thrombosis after successful implantation of drug-eluting stents. Jama. 2005;293(17):2126-2130.

23. Kuchulakanti PK, Chu WW, Torguson R, et al. Correlates and long-term outcomes of angiographically proven stent thrombosis with sirolimusand paclitaxel-eluting stents. Circulation. 2006;113(8):1108-1113.

24. van Werkum JW, Heestermans AA, Zomer AC, et al. Predictors of coronary stent thrombosis: the Dutch Stent Thrombosis Registry. J Am Coll Cardiol. 2009;53(16):1399-1409. 
25. Antoniadis AP, Mortier P, Kassab G, et al. Biomechanical modeling to improve coronary artery bifurcation stenting: expert review document on techniques and clinical implementation. JACC Cardiovasc Interv. 2015;8(10):1281-1296.

26. Nakazawa G, Yazdani SK, Finn AV, Vorpahl M, Kolodgie FD, Virmani R. Pathological findings at bifurcation lesions: the impact of flow distribution on atherosclerosis and arterial healing after stent implantation. J Am Coll Cardiol. 2010;55(16): 1679-1687.

27. Zimarino M, Corazzini A, Ricci F, Di Nicola M, De Caterina R. Late thrombosis after double versus single drug-eluting stent in the treatment of coronary bifurcations: a meta-analysis of randomized and observational studies. JACC Cardiovasc Interv. 2013;6(7): 687-695.

28. Lassen JF, Holm NR, Stankovic G, et al. Percutaneous coronary intervention for coronary bifurcation disease: consensus from the first 10 years of the European bifurcation Club meetings. Eurolntervention. 2014;10(5):545-560.

29. Li G, Taljaard M, Van den Heuvel ER, et al. An introduction to multiplicity issues in clinical trials: the what, why, when and how. Int J Epidemiol. 2017;46(2):746-755.
30. Bangalore S, Toklu B, Patel N, Feit F, Stone GW. Newer-generation ultrathin strut drug-eluting stents versus older second-generation thicker strut drug-eluting stents for coronary artery disease. Circulation. 2018;138(20):2216-2226.

\section{SUPPORTING INFORMATION}

Additional supporting information may be found online in the Supporting Information section at the end of this article.

How to cite this article: Kogame N, Chichareon P, De Wilder $\mathrm{K}$, et al. Clinical relevance of ticagrelor monotherapy following 1-month dual antiplatelet therapy after bifurcation percutaneous coronary intervention: Insight from GLOBAL LEADERS trial. Catheter Cardiovasc Interv. 2019;1-12. https:// doi.org/10.1002/ccd.28428 